femoral or iliac thrombosis and $13 \%$ with no thrombosis at all could expect moderate to serious symptoms. This finding is similar to that of a previous study ${ }^{7}$ in which we found postphlebitic symptoms in $20 \%$ of legs that had no thrombosis at the time they were first studied (three years earlier).

The lack of a simple correlation between the extent of the thrombosis and the symptoms can be explained in two ways. Either our analysis of the phlebogram does not highlight the critical aspect of the thrombosis that produces the late sequelaefor example, thrombosis in communicating veins-or another factor is implicated. Both are likely explanations. Phlebography cannot display every vein and the intricacies of the calf muscle venous pump are still a mystery. Possibly one small segment of thrombotic occlusion or valve destruction at a critical point within the pump may cause far more disorganisation of pump function than an extensive thrombosis elsewhere. But even if our crude assessment of the extent of the thrombosis gave no indication of the damage to the calf pump it is also likely that the postphlebitic syndrome is not just a result of calf pump damage but a combination of this damage and the tissue response to the resulting venous hypertension. We have shown that venous hypertension causes changes in capillary permeability and leads to the deposition of extravascular fibrin. ${ }^{8}{ }^{9}$ This fibrin must be cleared away and we have suggested that a deficiency of vein wall and interstitial fibrinolysis may be an important factor in producing the postphlebitic phenomenon. ${ }^{10}$ Blood fibrinolytic activity was measured at the follow-up examination of the patients in this study and there was just a statistically significant correlation $(p=0.05)$ between the symptom score and the blood fibrinolytic activity, but no definite conclusions should be made from this association without a prospective study.

These studies show that the postphlebitic leg syndrome is not as simple as its name suggests. It may not always be postphlebitic, and until we have a better understanding of the calf pump and the course of events between a thrombosis and the appearance of symptoms we should use the name with caution. The term "postphlebitic syndrome" is a useful clinical description but we must remember that an exclusive causal relationship between the thrombosis and the syndrome and the mechanisms of symptom production have not yet been established.

\section{References}

1 O'Donnell TF, Browse NL, Burnand KG, and Lea Thomas M. The socioeconomic effect of an ilio-femoral thrombosis. F Surg Res 1977;22: $483-8$.

2 Lea Thomas M. Phlebography. Arch Surg 1972;104:145-50.

3 Lea Thomas M, McAllister V. The radiological progression of deep vein thrombosis. Radiology $1971 ; 99: 37-40$.

4 Bauer G. A roentgenological and clinical study of the sequelae of thrombosis. Acta Chir Scand 1942; Suppl 74

${ }^{5}$ Browse NL, and Clemenson G. Sequelae of an ${ }^{125}$-fibrinogen detected thrombus. Brit Med $\mathcal{F} 1974$;ii:468-70.

6 Mudge M, Hughes LE. The long term sequelae of deep vein thrombosis BrF Surg 1978;65:692-4.

7 Young AE, Lea Thomas M, Browse NL. Comparison between the sequelae of surgical and medical treatment of venous thromboembolism. Br Med F 1974; iv:127-33.

8 Burnand KG, Clemenson G, Whimster IM, Browse NL. Extravascular fibrin deposition in response to venous hypertension. Brit $\mathcal{F}$ Surg 1976; $63: 660$.

${ }^{9}$ Browse NL, Burnand KG. The postphlebitic syndrome, a new look. In: Bergen JJ, Yao ST, eds. Venous problems. Yew Book: Chicago, 1978.

10 Wolfe JH, Morland M, Browse NL. The fibrinolytic activity of varicose veins. Br $\mathcal{F}$ Surg $1979 ; 66: 185-7$.

(Accepted 19 September 1980)

\title{
How long should patients with suspected myocardial infarction be under observation in hospital?
}

\author{
ANNELI POUKKULA, ESKO HUHTI
}

\section{Summary and conclusions}

Out of 368 patients admitted to hospital for chest pain and suspected acute myocardial infarction, 267 were discharged within 24 hours on the basis of the clinical picture, electrocardiogram, and serum activities of aspartate transaminase, alpha-hydroxybutyrate dehydrogenase, and creatine phosphokinase. The patients were followed up for 28 days, during which 17 were readmitted, two of them twice and one three times. Two of the patients were readmitted with non-fatal acute myocardial infarction, and two died. The patients had been primarily divided into two groups: those admitted with presumably non-coronary chest pain (77 patients) formed group 1 and those with obvious coronary chest pain (190 patients) group 2. Both deaths occurred in patients in group 2 but the incidences of events during the follow-up period were otherwise similar in the two groups, and some patients in both groups may have had small acute myocardial infarctions when first admitted.

Department of Medicine, University Central Hospital, SF-90220 Oulu, Finland

ANNELI POUKKULA, MD, physician

ESKO HUHTI, MD, associate professor
The decision to keep in hospital or discharge a patient with chest pain of recent onset can be made within 24 hours of admission. To discharge the patient acute myocardial infarction need not necessarily be excluded and conventional tests are enough to enable a decision to be made.

\section{Introduction}

Patients presenting at the emergency department of this hospital for obvious acute myocardial infarction are admitted direct to the coronary care unit. Patients presenting with chest pain in whom the diagnosis is not immediately clear, however, are first 6 admitted to the observation ward, for 24 hours at the most. If acute myocardial infarction is confirmed, or if chest pain continues or recurs, the patient is moved to the coronary care unit or sometimes to an ordinary ward; otherwise he is discharged. Thus the observation ward acts as a regulator between the emergency department and other wards, allowing the limited number of beds to be used efficiently.

The decision to discharge a patient from hospital or move him to the coronary care unit or another ward is based on the clinical picture, electrocardiogram, and serum activities of aspartate transaminase, $\alpha$-hydroxybutyrate dehydrogenase, and creatine phosphokinase. Recently the MB fraction of creatine phosphokinase has also been determined. We carried out a study 
to examine whether the decision to discharge a patient with chest pain from hospital after not more than 24 hours' observation can safely be based on the results of these tests.

\section{Patients and methods}

From February to June 1979,350 patients (178 men and 172 women) were admitted to the observation ward with chest pain and suspected acute myocardial infarction. A few were admitted two or more times during this period. Since we were concerned only with the short-term prognosis for these patients, which we defined as events taking place within 28 days after admission, we followed up the patients for 28 days. If the patient was readmitted more than 28 days after the primary admission he was treated as a new case and again followed up for 28 days. Thus each follow-up period of 28 days defined a "patient," the number of which, thus defined, was 368 . The average duration of stay in the observation ward was less than 24 hours. Patients with obvious acute myocardial infarction on admission were admitted direct to the coronary care unit and were not included in the study.

A standard 12-lead electrocardiogram was obtained and blood collected on admission and the next morning for the determination of aspartate transaminase, $\alpha$-hydroxybutyrate dehydrogenase, and creatine phosphokinase. The MB fraction of creatine phosphokinase was also determined, but the result of this test was not available until the patient had been discharged or moved to another ward. We personally interviewed each patient and reviewed all their hospital records and electrocardiograms.

The patients were classified into three groups according to the results of the investigations.

Group 1 (77 patients: 39 men, 38 women) comprised patients whose chest pain was atypical and not regarded as being of coronary origin, even though many of them also had coronary disease. Some had slight and non-specific $T$-wave changes on the electrocardiogram, and one showed changes consistent with pericarditis. Sometimes raised cardiac enzyme activities were noted, but these were considered to reflect a disease other than acute myocardial infarction. These patients were discharged home within 24 hours, or in a few cases moved to another ward (for cholecystitis, pancreatitis, pericarditis, etc).

Group 2 (190 patients: 103 men, 87 women) comprised patients whose chest pain suggested coronary origin but abated and who did not fulfil the criteria for group 3. They were discharged home within 24 hours with a diagnosis of "coronary pain, acute myocardial infarction not likely."

Group 3 (101 patients: 47 men, 54 women) comprised patients whose coronary pain continued or recurred and those with an electrocardiogram showing a new pathological $Q$ wave, ischaemic-type ST depression of $2 \mathrm{~mm}$ or more, or deep $\mathrm{T}$ inversion. If the electrocardiographic changes were equivocal or could not be interpreted the activities of at least two of the three enzymes measured were required to be clearly above normal with no other obvious reason for the increase-for example, pulmonary embolus, cholecystitis, liver disease, or alcohol consumption. The patients in this group were regarded as having unstable coronary insufficiency or acute myocardial infarction and were moved to the coronary care unit or another ward for further observation or treatment. Acute myocardial infarction was eventually definitely diagnosed in 50 , of whom nine $(18 \%)$ died within 28 days.

Enzyme activities were determined by the recommended methods. ${ }^{12}$ Isoenzymes of creatine phosphokinase were separated by electrophoresis (Helena Laboratories Zip Zone CPK method, Helena Laboratories, Beaumont, Texas) and the fractions measured with a densitometer (CliniScan, Helena Laboratories). The normal values were $\leqslant 40 \mathrm{U} / \mathrm{l}$ for aspartate transaminase, $\leqslant 320 \mathrm{U} / 1$ for $\alpha$-hydroxybutyrate dehydrogenase, and $\leqslant 170 \mathrm{U} / 1$ for creatine kinase.

We report here on the patients in groups 1 and 2 only. They were followed up for 28 days and the number of deaths, new acute myocardial infarctions, and readmissions during this period recorded, checks being made on the census lists and hospital records. The patients were asked to contact the emergency or outpatient department if they had any problems, but no formal follow-up examination was arranged if the patient was obviously well.

\section{Results}

The mean ages of the men were 52 (range 23-85) years in group 1 and 59 (29-81) years in group 2. The women had mean ages of 60 (35-92) and 65 (38-87) year's respectively. In other respects the results were largely similar for the men and women, so that the sexes are combined in the results presented below.

Coronary disease was common in groups 1 and 2, the numbers of patients with a history of myocardial infarction being $13(17 \%)$ and $71(37 \%)$ in the two groups respectively. The table shows the proportions of patients with appreciable arrhythmias, any recent electrocardiographic changes, and increased enzyme activities. In a few cases one or other of the test results was missing, and MB creatine phospho-

Numbers (\%) of patients with recent electrocardiographic changes, appreciable arrhythmias, and giving abnormal results to laboratory tests

\begin{tabular}{|c|c|c|c|}
\hline & \multicolumn{2}{|c|}{ Diagnostic classification } \\
\hline & & Group 1 & Group 2 \\
\hline \multirow{3}{*}{\multicolumn{2}{|c|}{ 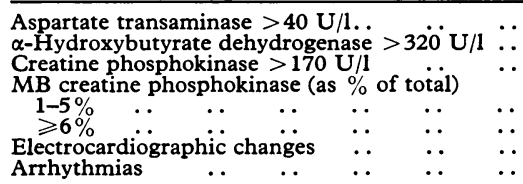 }} & $\begin{array}{l}10(12) \\
1(1) \\
12(15)\end{array}$ & $\begin{array}{r}21(11) \\
5(3) \\
41(22)\end{array}$ \\
\hline & & $\begin{aligned} & 18(31) \\
& 4(7) \\
& 8(10)\end{aligned}$ & $\begin{array}{r}12(38) \\
6(4) \\
28(15)\end{array}$ \\
\hline & & & $13(7)$ \\
\hline
\end{tabular}

kinase was determined only when the total creatine phosphokinase activity was $\geqslant 70 \mathrm{U} / \mathrm{l}$. Definitely increased fractions of $\mathrm{MB}$ creatine phosphokinase were found in four patients in group 1 and six in group 2.

Four patients $(5 \%)$ from group 1 were readmitted within 28 days for chest pain, one twice and one with acute myocardial infarction from which she recovered. None of the patients in group 1 died during the follow-up period.

Thirteen patients $(7 \%)$ from group 2 were readmitted (11 patients once, one twice, and one three times) during the follow-up period. One was admitted with acute myocardial infarction and recovered. Two of the patients died. One was a man aged 68 who had suffered from hypertonia and diabetes for years and from chest pains for three months. The day before admission he had had more severe chest pain when shovelling snow, and he walked to the emergency department the next morning. Acute myocardial infarction could not be diagnosed (MB creatine phosphokinase was not determined as the total creatine phosphokinase activity was less than $70 \mathrm{U} / \mathrm{l}$ ), and he was discharged without symptoms. Chest pain recurred a few days later, and he died suddenly at home six days after discharge. Necropsy showed a myocardial infarction about two weeks old. The other patient who died was a woman aged 68 who was readmitted twice and died of pulmonary oedema shortly after the second readmission. She had severe coronary disease, left ventricular failure, and various other diseases but no recent infarction could be found at necropsy.

One of the two patients with a non-fatal acute myocardial infarction was a man aged 66 who was readmitted two weeks after the first admission. He was a heavy smoker and had had slight ST-T changes but no arrhythmias when first admitted, and his enzyme values had been normal. The other was a 78-year-old woman in group 1 who was readmitted four weeks later. During the first admission she had had no electrocardiographic changes or arrhythmias, and cardiac enzyme values were normal.

\section{Discussion}

We have shown that it is usually possible in a short time (less than 24 hours on average) and with conventional investigations to choose from the patients with chest pain of recent onset those who may be safely discharged from hospital. We did not make exact note of the duration of pain, but it almost always lasted longer than half an hour, and typically one to three hours in the patients in group 2. Hence acute myocardial infarction was definitely possible in these patients, but any serious arrhythmia may endanger the patient's life early in the course of acute coronary insufficiency. ${ }^{3}$

Many of the patients in group 2 had some $M B$ creatine phosphokinase in their serum (table), and as this fraction is highly heart specific its increase has been interpreted as diagnostic of acute myocardial infarction. ${ }^{4-7}$ Nevertheless, conflicting opinions exist on the importance of MB creatine phospho- 
kinase, ${ }^{8} 9$ and recent evidence suggests that its release from the heart does not necessarily indicate irreversible myocardial necrosis. ${ }^{10}$ Even so, some of these patients may in fact have had acute myocardial infarction although it was not diagnosed. We do not suggest that the patients with confirmed acute myocardial infarction should be treated at home, but discharging the patient need not mean that the condition has been ruled out with certainty; and if a patient with a small infarction has no more symptoms, whether or not a definitive diagnosis can be made is probably of little consequence for the prognosis since the short-term prognosis is usually favourable. Indeed, Hill et $a l^{11}$ in their randomised trial of home versus hospital management for patients with suspected myocardial infarction showed that the results for the patients with an uncomplicated acute myocardial infarction were similar whether the patient was admitted to hospital or not.

Interestingly, the proportion of patients with $\mathrm{MB}$ creatine phosphokinase in serum in group 1 , which comprised patients whose chest pain was not regarded as of coronary origin, was almost as high as that in group 2. The patients in group 1 often had other disease that could give rise to chest pain, or the pain was vague or atypical, often with tender areas in the thoracic wall. Nevertheless, the results suggest that in this group of patients too the pain was sometimes of coronary origin, perhaps associated with a small acute myocardial infarction, and emphasise the difficulties of differential diagnosis in patients with acute chest pain.

One patient from each group had an acute myocardial infarction during the follow-up period, and the proportions of patients readmitted were of the same order in both groups, further suggesting their relative similarity. The two deaths, however, occurred in patients in group 2. The death of the 68-year-old man was unexpected, but even in retrospect there was no reason to have kept him in hospital any longer. He was symptom free when he left and had no electrocardiographic evidence of myocardial infarction, and serum enzyme activities were normal. The findings at necropsy showed that his myocardial infarction was about one week old when he was first admitted and he died two weeks after onset.

Mulley et $a l^{12}$ showed that patients admitted to coronary care units with suspected acute myocardial infarction could be classified into three risk groups within 24 hours of admission. The patients who were without major complications, increased activity of total serum creatine phosphokinase, or electrocardiographic evidence of transmural infarction during the first day could be designated low-risk patients. Three per cent of these subsequently met clinical criteria for infarction, $2 \%$ had late complications in the coronary care unit, and none died in the hospital, where they stayed $7 \cdot 1$ days on average. Using the serum activity of aspartate transaminase in the first 24 hours resulted in an apparent improvement in discrimination between the patients with and without subsequent complications, but this improvement was difficult to detect statistically. The patients were treated in hospital longer than our patients and were not followed up after discharge, but on the whole our results and those of Mulley et al agree well.

New and supposedly more sensitive or specific methods are constantly being introduced into the diagnosis of acute myo- cardial infarction, two modern approaches being myocardial scintigraphy ${ }^{13} 14$ and measurement of serum myoglobin concentration. ${ }^{15}$ The real value of a new diagnostic test often takes a long time to be established, ${ }^{16}$ and many of these tests are expensive and laborious. Myocardial scintigraphy and serum myoglobin and $\mathrm{MB}$ creatine phosphokinase estimations may be valuable aids, but their place in the diagnosis of acute myocardial infarction and even more in the practical treatment of patients remains to be determined, and they may be dispensable. The decision to discharge from hospital a patient with recent chest pain may be confidently made with more familiar investigations in a short time.

We thank the staff of the observation ward for valuable help in compiling the data for this study.

Requests for reprints should be addressed to Dr A Poukkula.

\section{References}

1 Committee on Enzymes of the Scandinavian Society for Clinical Chemistry and Clinical Physiology. Recommended methods for the determination of four enzymes in blood. Scand f Clin Lab Invest 1974;33:291-306.

${ }^{2}$ Committee on Enzymes of the Scandinavian Society for Clinical Chemistry and Clinical Physiology. Recommended method for the determination of creatine kinase in blood. Scand $\mathcal{F}$ Clin Lab Invest 1976;36:711-23.

${ }^{3}$ Mackintosh AF, Crabb ME, Brennan H, Williams JH, Chamberlain DA. Hospital resuscitation from ventricular fibrillation in Brighton. Br Med F 1979;i:511-3.

${ }^{4}$ Konttinen A, Somer H. Specificity of serum creatine kinase isoenzymes in diagnosis of acute myocardial infarction. $\mathrm{Br} \mathrm{Med} \mathcal{f} 1973$;i :386-9.

5 Varat MA, Mercer DW. Cardiac specific creatine phosphokinase isoenzyme in the diagnosis of acute myocardial infarction. Circulation $1975 ; 51: 855-9$.

${ }^{6}$ Roberts R, Gowda KS, Ludbrook PA, Sobel BE. Specificity of elevated serum MB creatine phosphokinase activity in the diagnosis of acute myocardial infarction. Am $\mathcal{F}$ Cardiol $1975 ; 36: 433-7$.

${ }^{7}$ Shell WE, Kligerman M, Rorke MP, Burnam M. Sensitivity and specificity of $\mathrm{MB}$ creatine kinase activity determined with column chromatography. Am $\mathcal{F}$ Cardiol 1979;44:67-75.

${ }^{8}$ Marmor A, Keidar S, Grenadir E, Palant A. MB isoenzyme of creatine phosphokinase. Indicator of ischemia in coronary arterial disease. Chest $1979 ; 75: 88-90$.

${ }^{9}$ Lindsey D, Navin T, Finley P. Meaning of elevated CK-MB. Am Heart $\mathcal{F}$ 1979;98:405-6.

10 Brown PR, Chiu RCJ, Mulder DS. Does CPK-MB leakage necessarily indicate myocardial necrosis ? A correlative ultrastructural and electrophysiologic study in cardiac surgery patients. Chest $1979 ; 76: 370-1$.

11 Hill JD, Hampton JR, Mitchell JRA. A randomised trial of home-versushospital management for patients with suspected myocardial infarction. Lancet $1978 ; \mathrm{i}: 837-41$.

12 Mulley AG, Thibault GE, Hughes RA, Barnett GO, Reder VA, Sherman EL. The course of patients with suspected myocardial infarction. The identification of low-risk patients for early transfer from intensive care. $N$ Engl f Med 1980;302:943-8.

13 Walsh WF, Karunaratne HB, Resnekov L, Fill HR, Harper P. Assessment of diagnostic value of technetium-99m pyrophosphate myocardial scintigraphy in 80 patients with possible acute myocardial infarction. Br Heart $\mathcal{F} 1977 ; 39: 974-81$.

14 Joseph SP, Pereira-Prestes AV, Ell PJ, Donaldson R, Somerville W, Emanuel RW. Value of positive myocardial infarction imaging in coronary care units. $\mathrm{Br}$ Med $\mathcal{F} 1979 ; \mathrm{i}: 372-4$.

15 Stone MJ, Waterman MR, Harimoto D, et al. Serum myoglobin level as diagnostic test in patients with acute myocardial infarction. Br Heart $\mathcal{F}$ 1977;39:375-80.

${ }^{16}$ Ransohoff DF, Feinstein AR. Problems of spectrum and bias in evaluating the efficacy of diagnostic tests. $N$ Engl $\mathcal{F}$ Med 1978;299:926-30.

(Accepted 9 September 1980)
ONE HUNDRED YEARS AGO The problem of supplying seawater to the inhabitants of the metropolis appears likely to be practically solved. It is announced, without incurring the outlay proposed by the promoters of a company who unsuccessfully sought powers, during the recent session of Parliament, to lay pipes from Brighton to London, and without any disturbance of the streets and consequent interruption of traffic, the Great Eastern Railway Company undertake to supply sea-water to any part of London within their ordinary delivery at the rate of sixpence for three gallons. The water is brought from Lowestoft, and delivered at any address in air-tight cans for the price named; and an additional convenience to the purchaser is that the cans will, if required, be left until the following day, when the company's vans will call for them, without any extra charge. If the scheme be found to be remunerative, it will probably be adopted also by other railway companies who have sea-side stations; and probably inland provincial towns will ultimately be included in the service. It will, at all events, show whether a demand for sea-water really exists. (British Medical fournal, 1880.) 